\title{
A PRELIMINARY STUDY OF LEAD CHROMATE
}

\section{BY E. E. FREE}

This work was undertaken in the endeavor to determine if possible in what way and to what extent the character of precipitated lead chromate varied with the conditions of precipitation. If satisfactory results were obtained by purely chemical methods it was intended next to study the electrolytic precipitation of lead chromates, the work forming one step in an extended study of the electrolytic precipitation of pigments, which is in progress at Cornell. No work has been done on electrolytic precipitation and only a beginning made on the study of the chemical precipitation. As, however, there is no possibility of my being able to carry the work further, it has seemed desirable to publish the results (obtained in the spring of I906) in the hope that they may prove interesting and suggestive to other investigators.

\section{THE CHROMATES OF LEAD Neutral Chromate-- $\mathrm{PbCrO}_{4}$}

The neutral chromate is formed by the reaction of any neutral lead salt with an acid or neutral solution of any chromate or bichromate. It is ordinarily prepared by the precipitation of a lead salt--nitrate or acetate--by potassium chromate, and so formed it is a brilliant yellow, cryptocrystalline powder practically insoluble in water ${ }^{1}$ and decomposed by strong acids ${ }^{2}$ or alkalis. ${ }^{3}$ Weak solutions of alkalis or alkaline carbonates change it more or less completely into one or other of the basic salts.

Lead chromate occurs native as crocoite or crocosite

10.2 mg. per liter at $1 \mathrm{r}^{\circ}$. Kohlrausch and Rose: Zeit. phys. Chem., I 2, 24 I $(180,3)$.

2 Vauquelin: Ann. Chim. Phys. [I], 25, $106(1 ; 98)$. Schwartz: Dingl. Polyt. Jour., 186, 31 (186-). Duvillier: Comptes rendus, 76, 1353 (1873).

${ }^{3}$ Tauduelin: loc. cit. Brandenhurg: Scher. Nord. Ann., 3, 61 (1819). Rosenfeld: Jour. prakt. Chem. [2], 15, 2.39 (Is;). Lachaud and Lepierre: Bull. Soc. Chin. Paris $[3], 6,2,30-2,32$ (1891). 
and was known as such long before its true nature was suspected. In it Vauquelin in I797 discovered the element chromium. It occurs in transparent orange-red monoclinic prisms with a yellow streak. Artificial crystals of lead chromate are claimed to have been produced by all the following ways:

I. By placing solid potassium chromate and lead nitrate in separate cylinders set in a wide dish and filling the dish with water over the tops of the cylinders. ${ }^{1} \quad \mathrm{PbCrO}_{4} .2 \mathrm{PbO}$ is also obtained.

2. By allowing solutions of a lead salt and a chromate to diffuse into each other through a porous diaphragm. ${ }^{2}$

3. By adding a solution of potassium bichromate drop by drop to a solution of lead nitrate in nitric acid. ${ }^{3}$

4. By placing a lead-platinum couple in a solution of chromic chloride in a sealed tube. ${ }^{4}$

5. By dissolving powdered lead chromate in dilute nitric acid ( $\mathrm{I} / 5$ to $\mathrm{I} / 6$ full strength) at $100^{\circ}-150^{\circ}$, filtering, and allowing the solution to cool slowly."

6. By running a slow stream of a solution of lead acetate into a solution of chromic oxide in nitric acid. ${ }^{6}$

7. By heating to fusion a mixture of lead chromate and potassium chromate. ${ }^{7}$

The artificial crystals resemble the natural crocoite in color and other properties.

An unsuccessful attempt was made by the author to produce crystals of $\mathrm{PbCrO}_{4}$ by allowing solutions of potassium chromate and lead nitrate to diffuse together. The solutions were in the arms of a $U$ tube, the bend of which was occupied by a saturated solution of sodium nitrate.

${ }^{1}$ Drevermann: Liebig's Ann., 87, 120 (1852);89, 36 (1853).

${ }^{2}$ Vohl: Ibid., 88, II4 (1893).

${ }^{3}$ de Schulten: Bull. Soc. Franç. Min., 27, I 29 (1904).

"Gmelin-Kraut: Handbuch anorg. Chem., Vol. I, p. 717 (18-7). The method is credited to Becquerel.

${ }^{3}$ Bourgeois: Bull. Soc. Chim. Paris [2], 47, 882 (1887).

B Mayer: Ber. chem. Ges., Berlin, 36, I743 (I903).

'Manross: Liebig's Ann., 82, 359 (I852). 
The clots of lead chromate obtained were composed of microscopic crystals only, and differed in no distinguishable particular from the precipitates prepared in the ordinary manner.

\section{Basic Lead Chromates}

The best known basic chromate is the pigment "chrome red" $-\mathrm{PbCrO}_{4} \cdot \mathrm{PbO}$ or $2 \mathrm{PbO} \cdot \mathrm{CrO}_{3}$. It may be made in the following ways:

I. By heating the neutral chromate with solutions of the caustic alkalis or alkaline carbonates ${ }^{1}$ or with calcium or barium hydroxide, ${ }^{2}$ etc., or even by long contact with these solutions (especially the caustic alkalis). alkali. $^{3}$

2. By precipitating the chromate in the presence of free

3. By dissolving the neutral chromate in solutions of the caustic alkalis and allowing these solutions to evaporate ${ }^{4}$ or to slowly absorb carbon dioxide. of lead. ${ }^{6}$

4. By combining chromate solutions with basic salts

5. By boiling $\mathrm{PbO}^{7}$ or $\mathrm{Pb}(\mathrm{OH})_{2}{ }^{8}$ or $\mathrm{PbCO}_{3}{ }^{9}$ or $\mathrm{PbCrO}_{4}{ }^{10}$ with solutions of potassium chromate, or by boiling $\mathrm{PbCrO}_{4}$ with two-thirds its weight of $\mathrm{PbO},{ }^{11}$ or with white lead, ${ }^{12}$ or by

${ }^{1}$ Grouvelle: Ann Chim. Phys. [2], I7, 352 (1821). Weber: Dingl. Polyt. Jour., 279, 2 I 2 (I\$oI). Göhel: Chem. Ztg., 23, 543 (1899).

"Ost: I ehrbuch tech. Chem., P. 470 (1890).

'Vauquelin: Ann. Chim. Plyys. [x], 70, 90 (1800). Faraday: Quart. Jour. Sci., 19, 155 (18 25$)$.

* Liebig and Wöhler: Pogr. Ann., 2I, 580 (58.31). Lechaud and Lepierre: Bull. Soc. Chim. Paris [.3], 6, 230 (I89r).

${ }^{5}$ Gmelin: Handbook Inory. Chem., Watts's 'Trans., Vol. V, p. 160 (I851). The process is credited to Hayes.

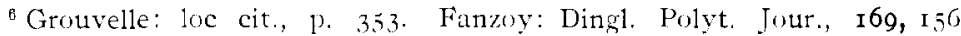
$(1863)$. Weber: loc, cit. Göbel: loc. cit.

'Gmelin-Kraut: Handbuch anorg. Chem., Vol. III, 1. 279 (187i).

Strömholm: Zeit. anorg. Chem., 38, 444 (rgo4).

${ }^{\circ}$ Dulong: Schweigger's Jour., 5, $3^{8}+(1812)$. See also Madans: Ann. Phil. N. S., 9, 303 (1825), and Göbel: 1oc. cit.

${ }^{10}$ Dulong: loc. cit. Göbel : loc. cit.

"Grouvelle: loc. cit. Badams: loc, eit.

12 Gruignet: Fabrication des Couleurs, p. Ior (I 888 ). 
heating two parts $\mathrm{PbO}$ and one part $\mathrm{K}_{2} \mathrm{CrO}_{4}$ made into a paste with water. ${ }^{1}$

6. By heating the neutral chromate for some time in contact with molten potassium nitrate ${ }^{2}$ or molten sodium chloride. ${ }^{3}$

7. By heating the neutral chromate to redness for some time. ${ }^{*}$

The true chrome red is a dark red crystalline powder. It has, however, been obtained in fine yellowish needles (from $\mathrm{KOH}$ )" and as an apparently amorphous yellow powder (by heating $\mathrm{PbCrO}_{4}$," "These lighter shades may possibly be due to the addition of water, ${ }^{7}$ and the formula $\mathrm{PbCrO}_{4}$. $\mathrm{Pb}(\mathrm{OH})_{2}$, has been suggested for the hydrated compound thus formed." Bodies intermediate in color between the neutral and the basic chromates may also be obtained by rendering the former only partially basic. These are the "chrome orange" pigments and are doubtless mixtures of $\mathrm{PbCrO}_{4}$ and $\mathrm{PbCrO}_{4} \mathrm{IbO}$. They deepen in shade with increase of basicity.

The basic chromate, $2 \mathrm{PbCrO}, \mathrm{PbO}$ or $3 \mathrm{PbO} .2 \mathrm{CrO}{ }_{3}$, occurs native as melanochoite or phönicite in clark red tabular

${ }^{1}$ Rosenfeld: Jour, prakt, Chem, [2], 15, $239(1,-5)$.

"I,iebig and Wobler: lnce cit. Fuss: Frdmann's four., I8, 22s (1833). Iachaud and I.epierre: (omptes remdte, i 10, 1035 (1880).

${ }^{3}$ I acliatud and Ieplerre: loc cit.

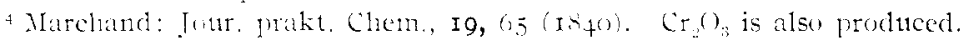

"Irachatud and Tepherre: Bull. Soc. Chim. Paris [3], 6, 230 (rSor).

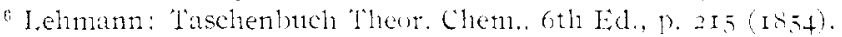

7 Grignet: Fabrication des couleurs, p. ISI (ISSG). This assumption is strengthened hy the fact that melandohte chatnes from dark red to lemonyellow on exposure to the air. Dand system of Mineralogy, 6th Ed., p. 9I4 $(\mathrm{ISO}) 2)$.

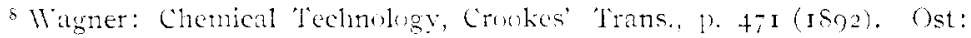
I.ehrtuch tech. Chem, P. tis (rigyo).

9 There is sme uncertinty about the composition of this compound. The formula given the text is that favored by Drevermann (loc. sit.), Lachaud and Lepierre (loc. cit.), Dana (System of Mineralogy, oth Fd., 1). 9I4 (IS()z)), ete. The formula $\mathrm{Pl}, \mathrm{CrO}_{4} .2 \mathrm{PbO}$ or $3 \mathrm{~Pb}_{3}\left(\mathrm{CrO}_{4}\right.$ is favored by Crmelin-Kraut (Handbuch anorg. Chem. VulII, p. 279 (1877)), and by Moissan (Traité Chim. Min., Vol. IV, p. In53 (1906)). 
crystals with a brick-red streak. It has been produced artificially in the following ways:

I. Together with $\mathrm{PbCrO}_{4}$, by the slow mixing by diffusion of solutions of potassium chromate and lead nitrate. ${ }^{1}$

2. By electrolysis through a connecting capillary tube of solutions of potassium bichromate and potassium plumbate. ${ }^{2}$

3. By heating the neutral chromate at a red heat for two hours in contact with molten sodium chloride. ${ }^{3}$

4. By the action of a solution of potassium bichromate on galena. ${ }^{4}$

Two other basic chromates have been prepared: $\mathrm{Pb}_{4} \mathrm{Cr}_{5} \mathrm{O}_{16},{ }^{5}$ and ${ }_{4} \mathrm{PbO} \cdot \mathrm{CrO}_{3} \cdot \mathrm{H}_{2} \mathrm{O} ;{ }^{6}$ and still another has been found native in South Africa. ${ }^{7}$

\section{Lead Dichromate- $\mathrm{PbCr}_{2} \mathrm{O}_{7}$}

The previous long-continued doubt ${ }^{8}$ as to the existence of a dichromate of lead has been recently resolved by Cox ${ }^{9}$ who has shown by phase-rule methods that it does exist, and is stable in contact with solutions containing at least 6.87 gram-molecules of $\mathrm{CrO}_{3}$ per liter. In contact with solutions of less concentration it is changed to the neutral chromate. It is a brick-red crystalline-powder.

\section{THE COLORS OF THE LEAD CHROMATES}

As the lead chromates are used principally for pigments their color is of great importance and much attention has

${ }^{1}$ Drevermann: I,iebig's Ann., 87, I 20 (1852); 89, I I (1853). See p. 2. of this paper.

2 Becquerel: Comptes rendus, 79, 85 (18-i4).

${ }^{3}$ Manross: Jiebig's Ann., 82, 359 (1 852 ). Lachaud and Lepierre: Bull. Soc. Chim. Paris [3], 6, $230(189 \mathrm{I})$.

${ }^{4}$ Meunier: Comptes rendus, 87, 656 (1878).

"Moissan: Traité Chim. Mineral, Vol. 1Y, p. 105.3 (1906).

- Strömholm: Zeit, anorg. Chem., 38, 443 (1904).

${ }_{7}^{7} \mathrm{PbO}_{3} \mathrm{CrO}_{3}$, Dawson, Mineralogical Mag., 6, xviii (1885).

8 Its existence had been affirmed by Preis and Rayman (Ber. chem. Ges. Berlin, $\mathbf{1}_{3}, 343$ (1880) ) and Mayer (Ibid., 36, r/43 (1903)) and denied by Schulernd (Jour. prakt. Chem. [2], I9, 38 (1879)), Lachaud and Lepierre (Bull. Soc. Chim. Paris [.3], 6, 23I (189I)), and Autenrieth (Ber. chem. Ges. Berlin, 35, $2063(\mathrm{I} 902)$ ).

a Jour. Am. Chem. Soc., 28, izor (1903). 
been given by investigators and manufacturers to processes and conditions of preparation which increase the purity and clarity of the color. Especially is this the case with chrome yellow and there have been proposed a large number of mutually contradictory methods, for each of which is claimed the supremacy in the production of good pigmentary material. It is neither possible nor desirable to enter into a detailed discussion of these processes, but it may be interesting to indicate certain facts which are conceded by all or nearly all investigators, and certain lines of suggestion which are especially important.

\section{Basicity and Color}

It is evident from the first part of this paper that the effect of increasing the basicity of the normal chromate is to "deepen" the color and displace the maximum spectral intensity toward the red. By, therefore, preparing a series of bodies of varying basicity - which means probably varying relative quantities of $\mathrm{PbCrO}_{4}$ and $\mathrm{PbCrO}_{4} \cdot \mathrm{PbO}$--it is possible to obtain an unbroken series of colors varying from the pure yellow of the neutral chromate to the deep orange-red of the pure basic compound. The colors of the other basic chromates do not differ materially from that of $\mathrm{PbCrO}_{4}$. $\mathrm{PbO}-$ the variations among different samples of the same compound often being greater than the differences between the compounds. These variations in the color of the same compound are rather puzzling, as are also the yellow basic compounds already mentioned, or the transient violet compounds of apparently greater basicity which have been observed by Prinvault. ${ }^{1}$ They may be due to variations in basicity, hydration, etc., or to differences in the average size of the component crystals, as will be noted below. Excluding these exceptions increase of basicity always means darkening and reddening of the color and for the production of clear yellows it is therefore essential that the formation of basic salt be so far as possible avoided.

'Ding1. Polyt. Jour., 220, 259 (1875). 
This matter is of consiclerable practical importance and especially so on account of the extreme readiness with which the neutral chromate becomes basic during the process of preparation. The slightest trace of alkali, ${ }^{1}$ a temperature somewhat higher than usual," and probably many other unknown causes will suffice to give to the resultant precipitate a darker or "dirtier" color. This phenomenon-technically known as "turning" "-is the cause of frequent loss to manufacturers of colors as the material thus affected is usually quite useless for pigment.

It is possible, as will appear below, that turning is sometimes due to other and totally distinct causes, but in most cases it is doubtless the visible sign of a partial change of the chromate to the basic condition." This seems especially plausible in the light of the well-known fact that the presence of small amounts of free acid in the solution reduces the occurrence of turning to a minimum..$^{5}$ An excess of the chromate in the precipitating solutions seems to favor the occurrence of turning and an excess of lead to inhibit it."

${ }^{1}$ Vatuquelin: Ann, Chinn Phys [1], 7o, go (rsog). Thenard: Chinie, Vol. III, p. 5.33 (Is3t). Berrelius: Traté de Chimie, and Ed., Vol. IV, p. 109 $(1847)$; etc.

2Tauquelin: loc. cit. Anthon: Repertorium Pharmi, 76, I 29) (1842). Guignet: Fabrication des Couleurs, p. Ior (isss). Dammer, Handbuch chem. Tech., Vol. IV, $1.56+($ I 698$)$; etc. Anthon thinks that the lighter color of precipitates made in the cold is due to hydration.

${ }^{3}$ Preparations of chromate occasionally "turn" sume time after the precipitation is completed. This is probably due to the presence of alkali in the precipitate. Crouvelle found determinalle amounts of alkali in several orange-colored chromates (Ann. Chim. Phys. [2], I7, 35.3 (1825)).

${ }^{4}$ See the extetded investigation of turning by Dullo: Dentsche Illustr. Gewerbezeitung, 30, 272 (1865).

${ }^{5}$ Grodon: Ann. Chim. Phys. [I] 53, 220 (1805). Vauquelin: loc. cit. Dumas: Traité Chim. Aplliquée, Vol. $11,1 \% 584$ (IS3I). Hofmann: Chemische Industrie, Vol. II, p. 730 (1875). Weber: Dingl. Polyt. Jour., 279, 2 I2 (1891). Wagner: Chemical Technolugy, p) 47 ( $(1892)$.

${ }^{6}$ Weber: Jour. Soc. Chem. Ind., 4, 6i i (1885); ro, ; Io (1891). Dammer: Handbuch Chem. Tech., Vol. IT, P. $56+$ (1898). Hurst: Painter's Colors, 3rd Ed., p. izs (1901). Thurp): Inclustrial Chem., p. 2is (1905). Dullo (loc. cit.) dissents from this position. 


\section{Color and Crystal Size}

The color difference between crystallized lead chromate and the powdered compound is very marked. Natural crocoite is a deep orange and the artificial crystals are of the same color. The contrast with the ordinary brilliant yellow powder is very striking. This difference seems entirely due to the difference in size of particle, for when crocoite is finely powdered (as for instance in taking the streak) it shows a yellow scarcely less brilliant than that of the precipitated compound. The behavior of the basic chromates is quite analogous-the larger crystals corresponding to the deeper and redder shades. When chrome red is ground it takes on a decided yellow tinge." The streak of the dark melanochoite is a brick-red. ${ }^{3}$ Chromates prepared by the action of chromate solutions on lead hydroxide are redder when the hydroxicle is crystalline.

This behavior of pigments on grinding is probably to be explained as the effect of the light reflected from the external surfaces of the crystals in the ground powder. "The reflection spectrum of pigments arises from two distinct sources: (a) light reflected from the surface of the substance; (b) light reflected from the interior faces. The light reflected from the surface is nearly white. **** It is to the light internally reflected that the pigment owes its color.". The colored light reflected from a laver of pigment is that part of the incident light which has entered at least one of the crystals and been reflected from the posterior surface of that crystal, or from the surface of some other crystal situated more deeply within the mass. The colored light is, as above quoted, light reflected from "interior faces."

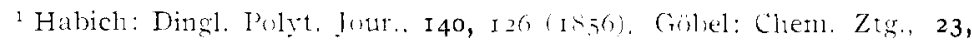

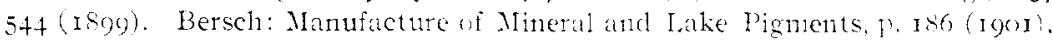

2 Fuss: Erdmann's Jour., I8, $2.30(1,33)$.

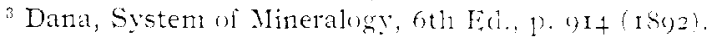

${ }^{4}$ Redlich, German Patent, ir,$- 1+8$, Jar. is, rgor ; see Chem. Zent., I90I, I, 288. It is possible that this may he an effect of a higher basicity of the crystallized hydrate.

o Xichols and Snow: Phil. Mag, [-3], 32, 423(180) The comparatively rare phenomena of "surtace culor" are, of course, excluded from consideration. 
In a more finely powdered pigment there will be obviously more surface per unit of mass, and the first of these "interior faces" will be on the average nearer the external surface of the layer; that is, the layer of colored material through which the internally reflected ray must pass, is less in the finely powdered material. It must therefore happen that the selective absorption which takes place in this ray will be relatively weaker or in common phrase, the "color" imparted to the ray will be less marked. In the terms of the curve expressing the relation between intensity and wave length in the reflected light, what happens may be expressed as a flattening of the curve or a decreasing of the accentuation of the maximum (or maxima) to which (with the physiological amendments below noted) the visual color is due. In the simplest case, therefore, the effect of pulverization of pigment should be simply to weaken the color or dilute it with white. ${ }^{1}$ The natural deduction is that the more finely a substance is powdered the more nearly white it will become, though a limit will finally be reached beyond which the individual particles become comparable in size to the wave length of light and hence change their optical behavior. Many colored substances are actually white or nearly white when finely pulverized, ${ }^{2}$ and nearly all colored bodies show a tendency in this direction.

Lead chromates, however, show a more complex behavior. The original reddish orange of crocoite changes on grinding to a clear yellow with no apparent trace of red, and this clear yellow is characteristic of all finely divided samples of $\mathrm{PbCrO}_{4}$. None of them become white. This seems to

${ }^{1}$ It is perhaps unnecessary to point out that visual white and spectral white are not necessarily the same thing. To the retina, red and yellow are the opposites of green and blue respectively, and each pair of opposites is algebraically summed. A light is visually white when the red is of equal physiologic intensity to the green and the yellow equal to the blue. This is not necessarily the same as the (idea1) spectral white in which the light is of equal intensity in all wave lengths.

${ }^{2}$ For instance, colored quartzes and fluorspars, garnet, obsidian, cobalt glass, manganous salts, nickel-ammonium salts, etc., etc. 
indicate not only a weakening of the total color as described, but an actual change in color, a shifting of the (visual) maximum from the red or orange into the yellow. The explanation of this effect requires a reference to the spectrum of the light reflected by lead chromate. This has been investigated by Nichols, ${ }^{1}$ who obtained the curve given in Fig. I, where the abscissae represent wave lengths and the ordinates intensities in terms of the spectrally uniform ideal white.

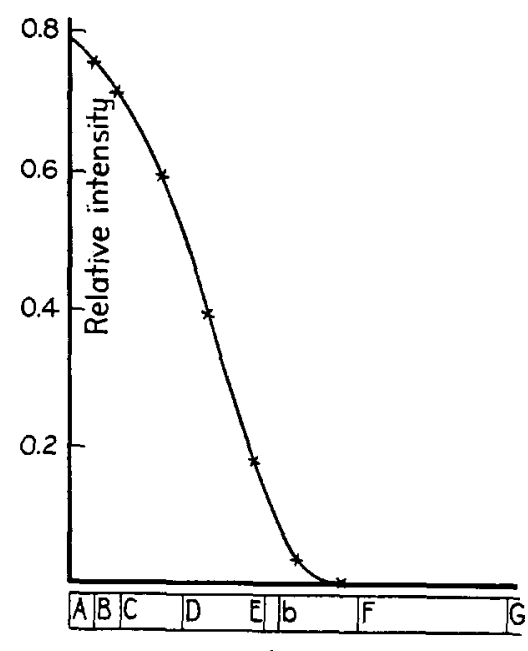

Fig. I

Spectrum of light reflected from lead chromate. Ordinates indicate relative intensities in terms of jeal white. After Nichols.

The curve may be legitimately considered as the representation of the light which is allowed to pass by a thin plate of lead chromate. It is the reverse of the ordinary absorption curve which indicates the parts of the spectrum in which the light is retained by the body under examination. Considering the curve in this way it is apparent that lead chromate absorbs practically all the blue and violet, most of the green and a considerable fraction of the yellow, but allows the red and probably the infra-red) to pass in much greater degree and in increasing proportion with increasing wave length. In other

\footnotetext{
${ }^{1}$ Am. Jour Sci. [3], 28, 345 (1884).
} 
words, there is an absorption area or "band" extending out of the ultra-violet into the visible spectrum, across the violet and blue, and shading off in the green and yellow. When the transmitted light is observed by the eye the green component is physiologically neutralized and orercone by the much larger quantity of red which has been permitted to pass, and the apparent color is a shade of yellow or orange with a greater or less tinge of red.

How will these relations be affected by change in the thickness of the plate of pirnent? Optical absorption bands in most bodies deepen on increase of thickness of the absorbing medium, and also spread out laterally, extending themselves into the regions of the spectrunl contiguous on either side. This spreading is not always symmetrical but is most frequently approximately so; and in the case under discussion, since definite data are lacking, it may be assumed that the general rule is followed. If, therefore, the thickness of the chromate plate be increased, the area of absorption, represented by the lower portion at the right-hand end of the curve, will extend itself toward the left, successively extinguishing the green, yellow, and red until in the extrene case the plate will have becone totally opaque to visible radiations. It is evident, therefore, that with increas of thickness of the absorbing plate the light transmitted by lead chromate should beconne (as indeed it does) more and more deeply red. It is perhaps worth noting that the extension of the absorption band into the green produces, in the apparent color, a disproportionate strengthening of the red, for the removal of the green releases and makes physiologically actire that fraction of the red which was previously employed in neutralizing in the retina the excitation due to the presence of the green.

If, on the other hand, the thichness of the absorbing plate be decreased, the absorption area will retreat toward the violet, the high part of the curve indicating more complete transmis:ion) will move toward the right, and, successively the yellow, the green, and the blue will be allowed to pass. In the limiting case, which is probably not actually realizable, 
the absorption area would move altogether beyond the visible spectrum, making the plate visually transparent. In intermediate cases the retreat of the absorption area and the progressive transmission of the green will progressively weaken the red by physiological neutralization, and thus make the yellow more and more prominent in the apparent color of the transmitted light. At the same time the yellow is further strengthened by its own progressively more complete transmission. It is therefore evident that with decrease in thickness of the plate of pigment the reddish tones of the apparent color will disappear and will be replaced by clear yellows. When the plates are very thin, the yellow itself is in part physiologically neutralized by the blue which begins to be transmitted, and the apparent color changes, never back to red (for there is always more green transmitted than blue), but to a paler and paler yellow and ultimately (in the limiting case) to white.

All this concerns the light transmitted through thin plates, but the application to the case in which light is reflected from a non-homogeneous layer of pigment is easy and obvious. It has already been pointed out that the colored fraction of the light reflected from (nearly) all bodies is light which has passed through a greater or less thickness of the material and suffered selective absorption. However, in the light reflected from a mass of powdered pigment there does come into play another factor - the reflection of white light from external faces of the crystals, as already discussed. The only effect of this is to dilute the color with white and render color differences less pronounced and less easily perceptible.

Practically then we should expect just what occurs. The larger crystals should be redder and the smaller more purely yellow. In very finely pordered samples the color should be much diluted with white and therefore very "clear." It is even conceivable that pulverization might be pushed to a point where the body would become white, though whether this is practically realizable is problematical. Of the facts as stated there is no question, but the explanations advanced can have 
no certain validity in the absence of direct experimental evidence.

If the above discussion is correct, it is possible to draw the practical deduction that the occasional cases of turning, which are apparently not due to increase of basicity, may possibly be caused by change in the coarseness of the precipitate. With increase of crystal size, the precipitate will take on a darker, redder, and less brilliant color. ${ }^{1}$ The color is practically the same as that caused by a slight basicity, and is exactly that obscrved when the pigment "turns." The differences in crystal size may be caused by variations in the concentration or temperature of the precipitating solutions, ${ }^{2}$ or may be due to secondary changes which take place when the precipitate is allowed to stand in contact with the mother liquor. It is well known that all crystalline precipitates do tend to increase in coarseness when allowed to stand in this way. $^{3}$

The discussion of the color changes, which correspond to changes in size of erystal in the case of the basic chromates, is impossible in the absence of reliable determinations of the spectra of these bodies. Their behavior is probably quite analogous to that of the neutral chromate. It is known that the yellow tinge shown by fincly ground chrome red is really present in the color at all times, for it makes its appearance when this pigment is combined with others which wholly or partially neutralize the red component. On account of this vellow tinge chrome red has been highly recommended for the production of flesh tints in painting. ${ }^{*}$

\section{Color and Temperature}

Lead chromate is one of the many so-called "metachro-

"In teclnical phrase, a "dirty color."

"It will he shown in the experinental part of this paper that such variations do have an influcnce on the crystal size.

3 Rothnnund: I, ̈̈slichkcit und l,̈̈sliclkeits beeinflussung, p. Iog (Igoj). Cf. also Chesnetu-Princiles théonticlues des methodes d'analyse minerale, pp. I $6-25$ (I006).

+ lins: locecit. 
matic" substances which change their color on heating. In this regard it is quite regular and follows the vast majority of other substances in that the maximum intensity moves toward the red with rise of temperature. ${ }^{2}$ When the neutral chromate is heated the color ranges through the orange to a very deep red, ${ }^{3}$ and in natural crocoite almost to black. ${ }^{4}$ Chrome red and melanochoite also darken in a similar manner when heated. ${ }^{5}$ The original colors are in all cases recovered on cooling; in fact, Houston and Thompson have shown that the general tendency of the color intensity to move towards the red with heating exists also in the reverse direction. Cooled to $-30^{\circ}$ or $-40^{\circ}$ the neutral chromate becomes a yellowish green, ${ }^{6}$

These colors are, of course, due directly to the temperature possessed by the body and have nothing to do with the permanent color differences seen in samples of lead chromate precipitated at different temperatures. These latter doubtless correspond to chemical or morphological modifications

1 Ackroyd: Chem. News, 34, 75 (18;6).

2Schönbein: Pogg. Ann. [2], I5, 263 (1838). Houston and Thompsin: Chem. News, 24, 177, 188 (1871). Ackroyd, and Nichols and Snow: loci citati. In connection with these observations of the effect of heating on color there is an interesting fact which, though quite different in cause, may serve as an illustration of the discussion in the last section. White metachromatic bodies almost invariably become yellow on heating. If metachromatism consist, as is prohable, of a general movement of intensity toward the red, the yellowing of white bodies means simply that the blue has been suppressed and the yellow is therefore no longer physiologically neutralized. The case is the same as with finely ground lead chromate, the green is able to neutralize the red, and only the yellow remains visible. On further heating, the green might disappear and the body would pass through the orange into the red, as does the chromate with increasing crystal size. In practice, the color changes on heating are soon complicated and obscured by light emitted by the body, as was found by Nichois and Snow to be the case with zinc oxide.

${ }^{3}$ Marchand: Jour. prakt. Chem., 19, 65 (1840). Berzelius: Traité cle Chimie, Vol. IV, p. Iog (1847). Dana: System of Mineralogy, 6th Ed., p. 914 (1892). Houston and Thompson: loc. cit.

${ }^{4}$ Dana: loc. cit.

${ }^{5}$ Houston and Thompson: loc. cit. Gmelin-Kraut: Handbuch anorg. Chem., Vol. III, p. 279 (1887).

${ }^{6}$ Houston and Thompson: loc. cit., p. 188. 
of the chromate crystals and are probably to be ascribed either to the effect of the temperature of precipitation on the size of the crystals or to the tendency of hot precipitation to cause an increase in the basicity of the precipitate.

\section{EXPERIMENTS ON THE CHEMICAL PRECIPITATION OF LEAD CHROMATE}

A molecular solution of $\mathrm{Pb}\left(\mathrm{NO}_{3}\right)_{2}$ was prepared by dissolving 331 grams of the crystalline salt in a liter of distilled water; $500 \mathrm{cc}$ of this solution were then diluted to one liter, $500 \mathrm{cc}$ of the resultant solution again diluted to one liter, and this process repeated until a series of 15 solutions was obtained, each nember of which had a concentration equal to one-half that of the preceding member. A similar series of solutions of $\mathrm{K}_{2} \mathrm{CrO}_{4}$ was then prepared, starting with a molecular solution (194.3 grams per liter) as before. Thus the solutions of corresponding number in the two series were chemically equivalent, the most concentrated being molecular, and the most dilute $\mathrm{M} / \mathrm{I}_{6} 6 \mathrm{~s}_{4}$.

Preliminary tests showed that the manner of mixing the solutions in making a precipitation had much influence on the character of the precipitate produced--probably because of concentration changes occasioned by incomplete mixing. This trouble was partially avoided by the following method of precipitation: $50 \mathrm{ce}$ of one of the solutions were placed in a $200 \mathrm{cc}$ beaker and stirred vigorously by meatis of an electrically operated stirrer, while $50 \mathrm{cc}$ of the equivalent solution of the other series were added in a slow stream. The mixture was then stirred for exactly five minutes, then taken out and the character of the precipitate examined. The same $50 \mathrm{cc}$ pipette was used in all cases to measure the solutions.

Accidental and irregular rariations in the precipitate are not by any means entirely avoided by this method of precipitation, but the results are much more uniform than by the ordinary method of pouring the solutions together. For precipitations at a temperature above that of the room, 
the beaker in which the precipitation was made was immersed in a dish containing water at the desired temperature. It seemed on trial that it made no constant difference in the character of the resulting precipitate whether the chromate solution was poured into the lead solution, or vice-versa; consequently, the former order was adopted in all cases. The precipitates were examined by the eye for color and state of aggregation (coarseness), comparison being made in each case between a whole series of precipitates made at different concentrations. Sedimentation tests were made by diluting the precipitates with their mother liquor until all contained the same quantity of precipitate in unit volume, and observing the rate at which these mixtures settled when placed in test-tubes. All of these methods of comparison gave more or less erratic results, which was probably due in part to faults in the method and in part to accidental variations in conditions. By far the most reliable indications were given by the microscope, and the best method of observation was found to be as follows: A small drop of the precipitate and mother liquor was placed on a slicle, covered with a cover glass, and the latter rubbed around a little to break up the aggregations of the crystals. The most uniform parts of the slide were then observed with a magnification of I Ioo diameters and the average size of the crystals determined by means of a micrometer eye-piece. The method of making color comparisons is described later.

\section{General Character of the Precipitates}

The precipitates are subject to very great irregularities. Two precipitates prepared as nearly as possible in the same manner will differ markedly in color, crystal size, tendency to flocculate, etc, etc. These variations are undoubtedly due to uncontrolled differences in the manner of precipitation, although what these differences may be it is impossible to say from the knowledge at present available. It must be understood, of course, that the variations in the precipitates are only relative. All the precipitates are yellow; all 
of them are composed of very fine particles. In fact, all have the characteristic properties of precipitated $\mathrm{PbCrO}_{4}$. The differences appear only on close examination.

It is believed that all the precipitates are crystalline, although in a few cases it was impossible to detect individual crystals. In most cases the precipitate appears under the microscope as a mass of interwoven needle-like prisms which are very easily broken up into short prismatic fragments. The crystal angles could not be determined. The smaller fragments almost invariably showed strong Brownian movements when suspended in water. Apparently in all cases lead chromate is first formed in colloidal solution and then precipitated, the rate of precipitation increasing with the concentration, $i$. e., the amount of electrolyte $\left(\mathrm{KNO}_{3}\right)$ in the solution. In the very dilute solutions lead chromate remains in colloidal solution for several days. The rapidity of precipitation is much hastened by heating.

\section{Effect of Temperature on Precipitation}

Series of precipitations from solutions of various concentrations were made at about $20^{\circ}$ and at $90^{\circ} \mathrm{C}$. From solutions of the same concentration the precipitates thrown down at the higher temperatures were uniformly darker in color and almost uniformly composed of larger crystals. The exceptions to this latter rule were found only in the higher concentrations, where the crystals were so small that accurate measurements became practically impossible. The precipitates thrown down at $90^{\circ}$ were much more uniform in character and apparently much less subject to the influence of accidental variations in conditions than were those made at $20^{\circ}$.

\section{Effect of Concentration of Precipitating Solutions}

Since accidental variations appeared to have less influence at high than at low temperatures, the influence of concentration was studied on precipitates prepared at $90^{\circ}$. A series of 15 of these precipitates was prepared from the solutions described on page I28. The precipitates from solutions of a concentration of $\mathrm{M} / 5 \mathrm{I} 2$ (No. Io) and less were so small 
in amount that comparisons of color were impossible. The precipitates from solutions $\mathrm{I}$ to 9 inclusive (concentrations $\mathrm{M}$ to $\mathrm{M} / 25^{6}$ ) were examined as to color by comparing each precipitate with every other precipitate in the series and noting in each case which was darker. When in any comparison a certain precipitate was called darker than another one, it was counted as a "score" for the darker precipitate. If no color difference could be detected between the two precipitates no score was counted for either. Thus when the comparisons were all finished and the scores belonging to each precipitate added up, the darkest precipitate of the series had the highest total of scores (since it had been most often marked as darker), and hence in a rough way the total of the scores marked against each precipitate indicated its "darkness" (or deepness, or redness) of color. ${ }^{1}$ The indications were made more accurate by giving each score more or less weight as the precipitate obtaining it was much or little darker than the one with which it was being compared. Thus if precipitate $A$ was much darker than precipitate $B$ it received a score of 5 ; if only slightly darker, of $\mathrm{I}$, etc.

A set of such scores obtained on precipitates from solutions $I$ to 9 is given in Table $I$. A higher total of scores indicates (at least roughly) a darker precipitate.

\section{TABLE I}

Effect of concentration of precipitating solutions on color of precipitate. Precipitations made at $90^{\circ}$

Number

I
2
3
4
5
6
7
8
9

$$
\begin{gathered}
\text { Concentration in gram } \\
\text { molecules per } \\
\text { liter }
\end{gathered}
$$

$I$
$I / 2$
$I / 4$
$I / 8$
$I / 16$
$I / 32$
$I / 64$
$I / 128$
$I / 256$

Color score

(Higher score means darker)

1 This method is one which has been devised and used by the experi mental psycholngists. 
These data are shown graphically in Fig. 2. On account of their great range it is impossible to represent the concentrations to scale. In the curve the numbers of the precipitates are simply set down in the order of concentration on the axis of abscissas, while the corresponding total scores are plotted as ordinates. Thus the point corresponding to a given precipitate stands at a height above the base line (axis of abscissas) roughly proportional to the comparative darkness of color of that particular precipitate.

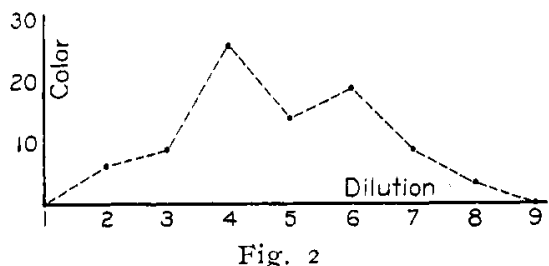

Relation of the concentration of the precipitating solutions to the color of the precipitate. Precipitations at $90^{\circ}$.

It is apparent that the curve shows a tendency to rise in the middle, which means that these precipitates are darker in color than the rest. There seems therefore to be a maximum of darkness or deepness of color in the precipitates from concentrations of $\mathrm{I} / 8$ to $\mathrm{I} / 32 \mathrm{~g}$ mols per liter. This conclusion is borne out in a general way by another series of precipitates, the results of which are given in Table II and shown in Fig. 3. This series was precipitated at $20^{\circ}$ instead of $90^{\circ}$, and only every other concentration was taken.

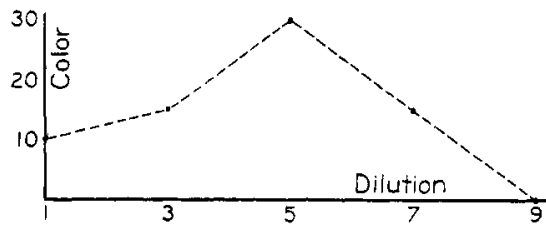

Fig. 3

Relation of the concentration of the precipitating solutions to the color of the precipitate. Precipitations at $20^{\circ}$. 
TAABL: II

Effect of concentration of precipitating solutions on color of precipitate. Precipitations made at $20^{\circ}$

\begin{tabular}{|c|c|c|}
\hline Number & $\begin{array}{l}\text { Concentration in gram } \\
\text { molecules per } \\
\text { liter }\end{array}$ & $\begin{array}{c}\text { Color score } \\
\text { (Higher score means } \\
\text { darker) }\end{array}$ \\
\hline I & I & IO \\
\hline 3 & I $/ 4$ & I5 \\
\hline 5 & I / I 6 & 30 \\
\hline 7 & $1 / 64$ & 50 \\
\hline 9 & I $/ 256$ & 0 \\
\hline
\end{tabular}

The effect of the concentration of the precipitating solutions on the size of the precipitated crystals was followed by measuring under the microscope a series of precipitates produced as already described. In each case there was noted: (I) the length of the longest crystals in the preparation; (2) the length of the shortest crystals (excluding broken crystais where possible); (3) the length which seemed to be approached most nearly by the largest number of crystals. ${ }^{1}$ These three lengths are designated as the "maximum," "minimum" and

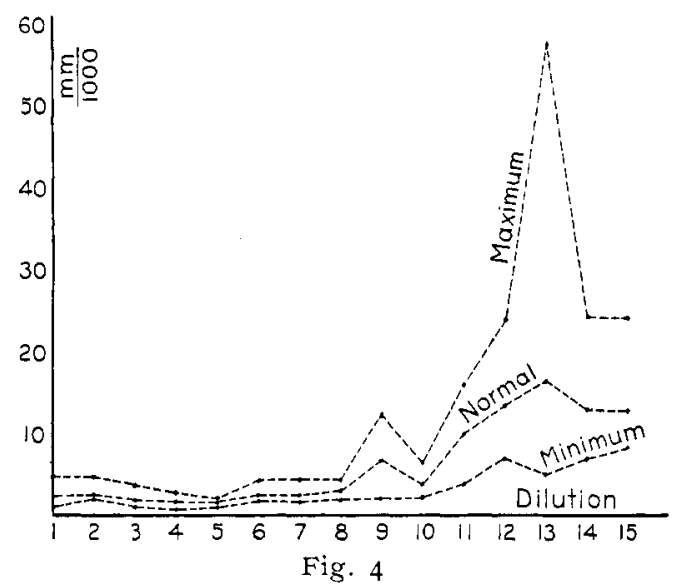

Relation of the concentration of the precipitating solutions to the size of crystals in the precipitate.

'Not necessarily the average length. 
"normal," respectively. It is believed that the normal length is at least a moderately exact index of the prevailing crystal size of the precipitate. The measurements are given in Table III and shown graphically in Fig. 4. In this curve as in others the concentrations are not plotted to scale.

\section{TABLE III}

Effect of concentration of precipitating solutions on the crystal size of the precipitate

\begin{tabular}{|c|c|c|c|c|}
\hline \multirow{2}{*}{ Number } & \multirow{2}{*}{$\begin{array}{l}\text { Concentration } \\
\text { ingran } \\
\text { molecules } \\
\text { per liter }\end{array}$} & \multicolumn{3}{|c|}{$\begin{array}{l}\text { Length of crystal in thousandths of a } \\
\text { millimeter }\end{array}$} \\
\hline & & Maximum & Minimum & Normal \\
\hline I & I & 4.8 & 0.8 & 2. I \\
\hline 2 & $I / 2$ & 4.8 & I. 6 & 2.4 \\
\hline 3 & $1 / t$ & 3.2 & 0.5 & I. 8 \\
\hline 4 & $1 / 8$ & 2.4 & 0.4 & I. 2 \\
\hline 5 & $1 / 16$ & I. 6 & 0.4 & I. 2 \\
\hline 6 & $1 / 32$ & 4.0 & I. 2 & 1.9 \\
\hline 7 & $I / 64$ & 4.0 & I. 2 & I.9 \\
\hline 8 & $1 / 128$ & 4.0 & I. 6 & 2.4 \\
\hline 9 & $1 / 256$ & I 2.8 & 1.6 & 6.4 \\
\hline IO & $1 / 512$ & 6.4 & 1.6 & 3.2 \\
\hline I I & $I / 1024$ & 16.0 & 3.2 & 9.6 \\
\hline I 2 & $I / 2048$ & 24.0 & 6.4 & 12.8 \\
\hline I 3 & $1 / 4096$ & 57.6 & 4.8 & 16.0 \\
\hline I 4 & $1 / 8192$ & 24.0 & 6.4 & I 2.8 \\
\hline 15 & $1 / 16384$ & 24.0 & 8.0 & I 2.8 \\
\hline
\end{tabular}

These measurements, of course, apply only to the length of the crystals, that being the dimension susceptible to most accurate measurement. Rough measurements of width and of area covered in the microscopic field show general agreement with those made on length.

In spite of considerable irregularities in the results, there is, as might be expected, an unmistakable tendency for the size of the crystal to rise with decrease of concentration, all three curves showing the same general tendency. This increase of the crystal size with decrease of concentration is in a general way a matter of common knowledge, and 
goes hand in hand with the well-known tendency, which was also observed in these experiments, for dilute solutions to require a much longer time for complete precipitation than do concentrated ones.

\section{Effect of Glue in the Solution}

A series of precipitates was prepared as above except that to each solution there had been added sufficient white glue (in solution) to make a concentration of Io grams per liter. These precipitates differed from the former ones mainly in the slowness with which they formed. Precipitates were formed immediately only in the most concentrated solutions, and in the solutions more dilute than $1 / 36$ molecular no solid precipitate was formed at all. The solutions simply turned yellow and opalescent, remaining thus for several months. The retarding action of the glue is less marked the higher the temperature of precipitation.

The precipitates from solutions containing glue are always composed of finer particles than those from ordinary solutions of corresponding concentration. In general the color is lighter.

\section{Summary}

The experimental results may be summed up as follows:

I. The largest crystals are obtained in hot and dilute solutions.

2. The precipitates from the most concentrated and the most dilute solutions are lighter in color than those from the intermediate solutions.

3. Glue retards precipitation and causes the formation of smaller crystals.

It will be noted that the results on the effect of the concentration of the precipitating solutions on color and on crystal size, are not, when taken together, in accord with the theories outlined in the second part of this paper. It has been found that the size of the precipitated crystals increases continuously with decrease in concentration. If then the color of the precipitate were directly and exclusively dependent on 
its coarseness, the color should show a continuous increase in darkness in the same direction. This it does not do. The curve of darkness of color shows a maximum at the moderate concentrations. This is probably due to the existence of a number of causes which are independently affecting the color of the precipitate. Indeed, that there are at least two such causes at work is proven by the very fact that the color curve shows an inversion. A curve corresponding to only one physical law shows no inversions. The two most probable causes of color change are varying basicity and varying size of crystal, and it may be that these two in combination are competent to produce the observed effects. More than this cannot be said until the conditions which control variations of basicity have been more fully and more accurately investigated.

The practical application of these results to the art of pigment manufacture depends upon the fact that a chrome yellow of small crystals possesses a clearer color and, other things equal, a greater covering power, than one of large crystals. Hence the best conditions for the manufacture of chrome yellow, other things being equal, should be cold and concentrated solutions mixed with rapid stirring under conditions which would most successfully prevent the formation of basic salt." What these last conditions are can only be settled by further investigation. It is an interesting question whether the presence of glue in the solutions would have any disadvantageous effect. The matter of oil absorption

${ }^{1}$ It is possible that the recomnendations of concentrated solutions and the prevention of the formation of hasic salt are nutually incompatible. It may be that the use of concentrated solutions would in itself cause the precipitate to become partially basic. It is claimed by many pigment experts that this is the case. If so, it would be necessary for practical purposes to reach a compromise between, on the one hand, the tendency of dilute solutions to produce coarse precipitates; and on the other, the tendency of concentrated solutions to induce basicity. To this cuestion, as to others, a complete answer cannot be given without further investigation of the production of the basic salts. The data of lable I would seem to indicate that very concentrated solutions are not, however, incompatible witl low basicity. 
is another important question which must some day be taken up.

The results so far obtained must, of course, be considered as tentative and as subject to revision. The methods of testing the character of the precipitate leave much to be desired, and the variables affecting the character are not yet controlled adequately. Some means should be devised whereby all the precipitations could be made under exactly the same conditions of mixing of the two solutions, of stirring, etc. If we had such means, work on the character of the precipitates formed from other lead salts or from solid lead compounds, or in the presence of colloids, organic liquids, solid particles, etc., etc., ought to be both interesting and valuable.

While the net results of this investigation have not been large, the paper will have served its purpose if it calls attention to the interesting possibilities involved in a systematic study of the conditions affecting the production and properties of pigments.

The investigation was suggested by Professor Bancroft and carried on under his direction. I am glad to have opportunity of acknowledging my great indebtedness to him not alone in this matter but in many others. 